\title{
Kulturmöten i monsunen: Metodiska utmaningar i forskning om Sydöstasiens historia
}

\author{
Hans Hägerdal
}

Vad hände någonstans långt bort i Asien den 7 maj år 1668? Det var en tid då det asiatiska fastlandet fortfarande dominerades av några stora så kallade krutimperier. I Kina hade den manchuiska Qingdynastin etablerat sig och befann sig i en dynamisk fas. I Indien stod Stormogulernas rike fortfarande rycken, och samma sak gällde Safavidernas dynasti i Iran. Men längs Asiens kuster hade europeiska sjöfarare börjat nagga de gamla handelsnätverken i kanterna och levde bokstavligen rövare. På några ställen i Indien, Kina och Sydöstasien höll portugiserna sig fast och handlade med kläder, sandelträ och annat. På Filippinerna hade spanjorerna sedan länge upprättat en omfångsrik koloni som bland annat var mellanstation för det silver som exporterades från Amerika till Östasien. I Sydöstasiens havsländer hade holländarna stort inflytande och försökte skaffa monopol på att handla med kryddor och dominera Asiens sjörutter. Och runt de asiatiska kusterna svärmade engelska, franska och danska handelsskepp och försökte få sin del av den kommersiella kakan.

Den här dagen, 7 maj 1668, rådde det officiellt fred mellan Nederländerna och Portugal, och det var överhuvudtaget relativt fredligt i Europa. Mindre så i Sydöstasien. I en sandig vik på västsidan av den lilla indonesiska ön Leti, mittemot Timor, låg en flotta som bestod av 1819 korakoras, en sorts indonesiska utriggare, uppdragen på stranden. Besättningen bestod av drygt 400 soldater och sjömän, såväl portugiser som folk från öarna runtomkring, och till och med några holländska desertörer. Mot dem rörde sig en annan flotta med knappt 100 holländska soldater, väl försedd med skeppsartilleri. När de bägge flottstyrkorna fick se varandra påbörjade genast en våldsam strid. Holländarna försökte flera gånger ta sig in mot stranden för att bränna portugisernas skepp men dessa hade förskansat sig på en skogbevuxen klippa ovanför strandlinjen och hälsade holländarna med sina musköter. Till sist måste holländarna se sig slagna. Två nätter senare, efter en del förhandlingar, försvann den portugisiska flottan under natten i skydd av det becksvarta mörkret, blåsten och regnet som hällde ner.

Slaget vid Leti har aldrig funnit vägen till historieböckerna. Det holländska ostindiska kompaniet eller VOC, som har dokumenterat händelsen, höll inne med informationen och historien publicerades aldrig. Det var först nyligen som jag hittade den fullständiga storyn i en omfångsrik resedagbok i ett arkiv i Haag. ${ }^{1}$

\footnotetext{
${ }^{1}$ VOC 1267, Banda, Dagregister, sub 7 maj 1668, Nationaal Archief, Haag.
} 


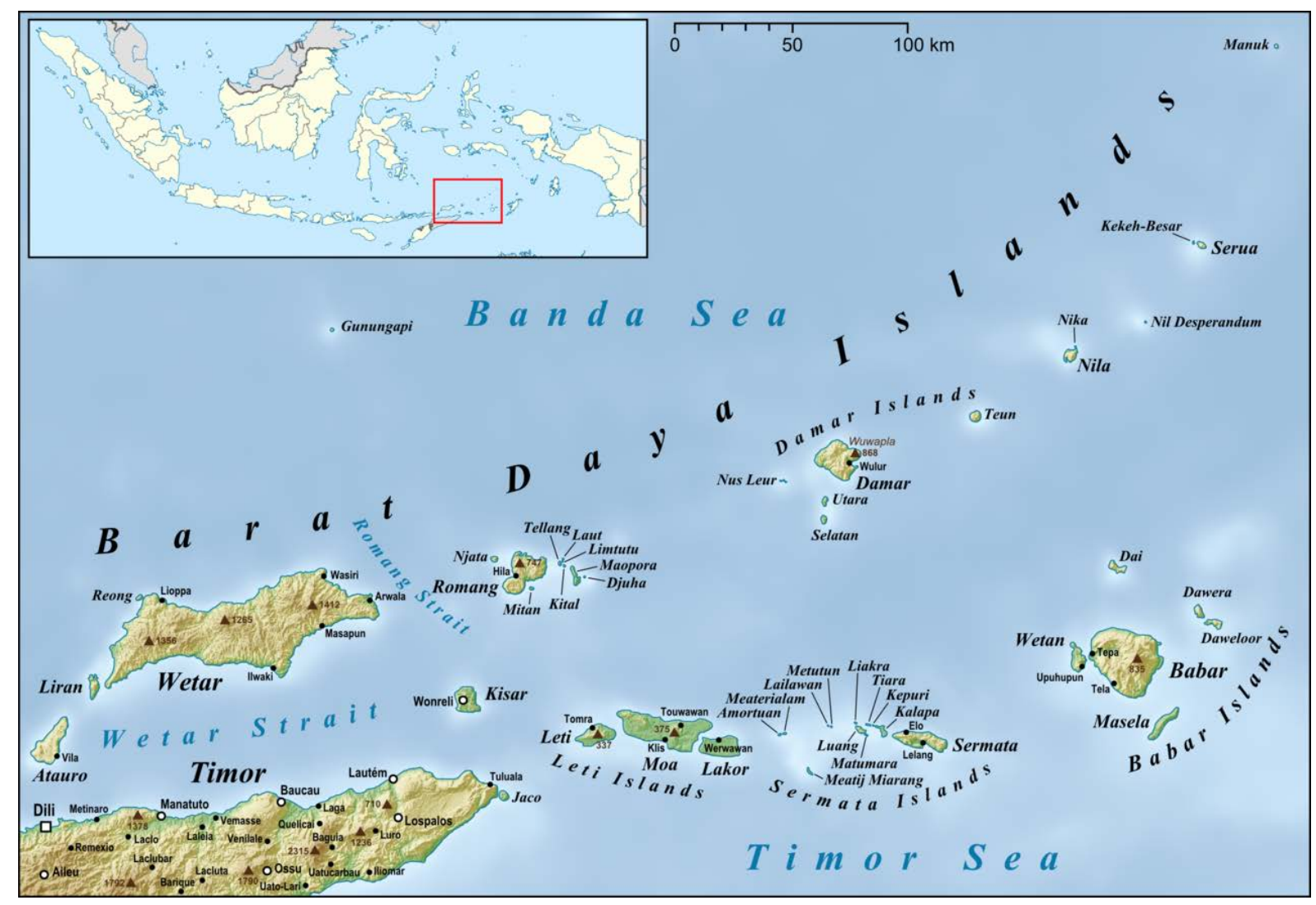

Karta 1. Del av östra Indonesien (Sydvästöarna i Moluckerna) och Östtimor. Källa: https://en.wikipedia.org/wiki/Wetar\#/media/File:Barat_Daya_Islands_en.png. CC BY-SA 3.0.

Historien om bataljen säger oss en hel del, dels om problemen med att forska om det maritima Asien i äldre tid, och dels om hur koloniala krafter kunde fungera. Vi kan börja med det senare. Holländare och portugiser var officiellt goda vänner sedan några år, men ändå rök de ihop i en blodig batalj i en del av världen som få européer visste något om. Händelserna i öster följde sin egen våldsamma logik. Den portugisiska flottan hade rövat och plundrat på öar som holländarna ansåg låg inom deras sfär - trots att de nästan aldrig besökte dem och portugiserna fann det oklart vem de tillhörde. I själva verket fick händelsen en viss betydelse eftersom den drev på kolonialismen i området, med konsekvenser fram till idag. Efter bataljen inbjöd en hövding på en av de drabbade öarna holländarna att upprätta ett fort på ön, Fort Delfshaven på Kisar som fortfarande finns till beskådande (Rodenwaldt 1927). Holländarna passade också på att upprätta allianser med flera småkungadömen på Östtimor som portugiserna hade vissa anspråk på. Portugiserna i sin tur reagerade med att anfalla Östtimor och lägga under sig kusttrakterna utan att holländska ostindiska kompaniet lyfte ett finger. Det fanns helt enkelt inte tillräckligt stora kommersiella intressen att försvara, trots att man kunde köpa t ex vax, sandelträ och slavar. Så kom Östtimor att styras av Portugal fram till 1975 under det att övärlden i övrigt blev till Nederländska Ostindien. Följderna av det ser vi än idag på den politiska kartan.

Det här är en liten del av det som jag har forskat om under senare år. Mitt fokus har rört sig kring historiska processer i Sydöstasien, och framför allt delar av det som idag är Indonesien, där jag har tittat på tidig kolonial inverkan och inhemsk respons. Tidsmässigt har det spänt ungefär mellan 1500- och 1900-talen. En av de fascinerande aspekterna är att det 
finns så mycket kvar att upptäcka. Det finns många hyllkilometer med material som de gamla kolonialmakterna lämnade efter sig, och en stor del har aldrig egentligen gåtts igenom. Jag återkommer strax till problemet med att använda europeiskt material för att skriva asiatisk historia. Genom att mödosamt gå igenom originaldokument som beskriver handel och politik under den förmoderna eran kan man få en fullständigare bild av hur olika intressen och grupper möttes och ledde fram till det moderna Asien. Icke överraskande blir bilden mer komplicerad och mindre entydig ju djupare man gräver i källorna.

En sådan komplikation är de inhemska folkgruppernas agens. Frågan om hur man beskriver koloniala processer på ett sätt som är rättvisande för både europeiska och inhemska grupper borde vara lätt besvarad: man tittar både på europeiska och asiatiska källtexter utan att se de senare som någon sorts 'second-best'-källor som man tar till när det västerländska stoffet tryter. Det fungerar till en viss grad. I de flesta asiatiska länder som påverkades av kolonialismen finns en viss corpus av krönikor, rättsliga dokument, religiösa och litterära texter, och så vidare. De kan hjälpa oss att förstå kulturmötena i viss utsträckning. Problemet är att asiatiska originaldokument ofta är sämre bevarade än europeiska. Det gäller speciellt i tropiska områden som Sydöstasien. På öar som Sumatra, Java och Bali skrev man ofta på tunna skivor som beretts av lontarpalmens blad. I hett och fuktigt klimat försvann texterna efter en tid om de inte kopierades. I andra regioner som Flores, Timor och södra Moluckerna skrev man överhuvudtaget inte dokument i någon utsträckning. I de småskaliga samhällen som fanns där var det ovanligt att någon kunde läsa eller skriva.

Det betyder att vi i asiatiska kustländer ofta har en enormt detaljerad bild av vad som hände, som dock bygger på europeiska dokument. Speciellt det holländska ostindiska kompaniet dokumenterade snart sagt varje kokosnöt som köptes eller såldes. Alla detaljer gör att vi ändå kan komma inhemska personers och gruppers agens inpå livet. Källor från europeiska handelsplatser innehåller till exempel vittnesmål eller referat av rättsfall som ibland rentav låter oss höra kvinnors och slavars röster - människor som sällan kommer till tals i äldre asiatiskt källmaterial.

Genom att se i vilka sammanhang inhemska personer förekommer i materialet och hur de framställs, går det också att säga en del om hur de sannolikt har resonerat för att hantera, dra nytta av eller göra motstånd mot kolonialismen. I vårt exempel med konflikten från 1668 rörde det sig inte om någon rent europeisk affär. Med i den portugisiska flottan fanns också soldater och sjömän från öarna Alor, Pantar, Timor och Sulawesi. Intressant nog låg en del av platserna i själva verket under holländska Ostindiska kompaniet, men folk därifrån föredrog ändå att delta i portugisernas rövartåg och sedan konfrontera holländarna. Det visar att man hade ett visst utrymme för att göra strategiska val i en värld där européerna ännu inte befann sig i full kontroll trots anspråk på att man behärskade vidsträckta områden.

På den holländska sidan bad hövdingen på ön Kisar uttryckligen att hjälpa till att bygga ett fort åt holländarna så att de kunde lägga in en garnison. Scener som denna är vanliga i Asien: inhemska ledare ber aktivt att en kolonialmakt ska etablera sig. Det är besvärande för modern asiatisk historieskrivning som brukar ha en antikolonial udd. För en lokal ledare på 1600talet, långt innan nationalism var påtänkt, var det nog logiskt: i småskaliga och sårbara samhällen i Sydöstasiens övärld vägde behovet av beskydd över nackdelarna av kolonialmaktens närvaro. Europeiska krav på handelsmonopol och betungande kontributioner var något man fick försöka leva med, hellre än att inte leva alls. Man har kallat det här 
ömsesidig parasitism: den tidiga kolonialismen exploaterade afrikanska och asiatiska grupper, som i sin tur sökte att utnyttja kolonisatörernas närvaro för att vinna fördelar i en orolig och våldsam miljö (Roque 2010).

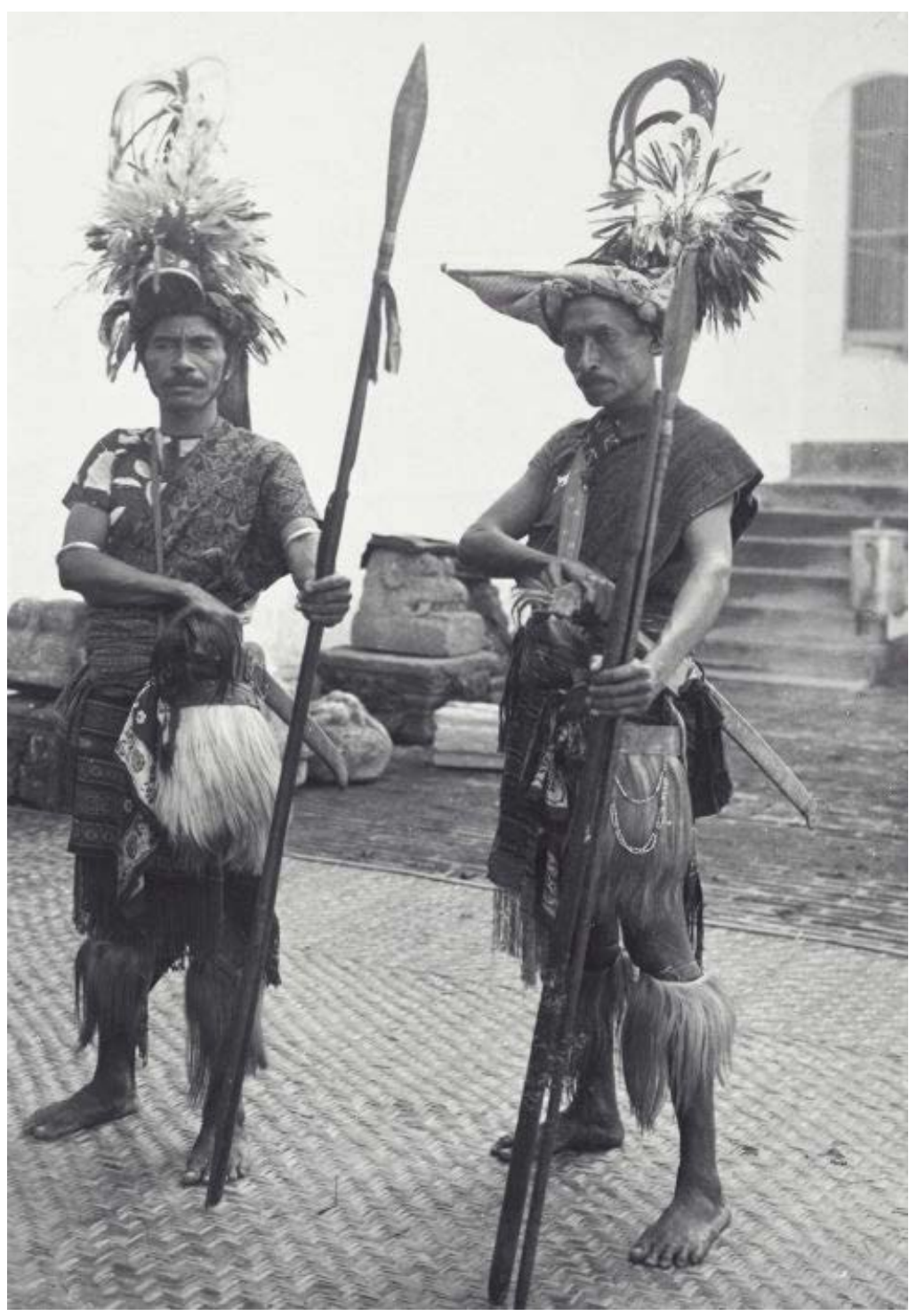

Bild 1. Krigare från den moluckiska ön Kisar, fotografi från sen kolonialtid. Källa: https://en.wikipedia.org/wiki/Kisar\#/media/File:COLLECTIE_TROPENMUSEUM_Portret_van twee_krijgers_uit_Kisar_bij_de_decorstukken_van_een_fotostudio_TMnr_60039093.jpg. CC BY-SA 3.0.

Genom att studera utförliga arkivkällor som européer lämnade efter sig har vi också goda möjligheter att se vad som hände i kontaktzonerna, det vill säga där inhemska och främmande grupper möttes och interagerade. En mycket naturlig sådan sak är sex. Före den tropiska medicinens genombrott i mitten av 1800-talet, nya säkrare och snabbare båttyper och Suezkanalens öppnande 1869 var det ganska ovanligt att kvinnor medföljde den sex månader långa och farliga turen från Europa till Sydöstasien. Det betydde att sjömän, soldater och administratörer fick hitta lokala fruar, asiatiska eller eurasiska. Tidig kolonialism innebar alltså alltid en viss mix mellan kulturer, en hybriditet. Det gällde holländarna men kanske 
ännu högre grad portugiserna. I den ostindiska övärlden fanns det få portugiser födda i Europa, och många hade inte alls några europeiska förfäder utan tillhörde familjer som hade tagit upp katolicismen och portugisisk identitet. Under långa perioder styrdes den portugisiska samfälligheten i Flores och Timor av personer som hade 100\% asiatiskt blod i ådrorna (Boxer 1947). Det är ett av många exempel på att kolonialismen inte alltid är ett så entydigt fenomen. Naturligtvis ska inte det här misstolkas så att förhållandena präglades av harmoni. I själva verket var den portugisisk-asiatiska gruppen känd som hårdhänta herrar som hänsynslöst anföll områden som inte lydde deras vilja - precis som holländarna för övrigt gjorde på sin kant.

Det leder oss in på frågan om ekonomisk exploatering. Kolonialism handlar inte alltid om cyniskt rationell ekonomisk exploatering eftersom det också finns strategiska och ideologiska skäl till att ett land tillägnar sig ett område. I portugisernas fall fanns alla tre skälen: att tillägna sig kryddproduktion, att motverka islam och skapa kristna områden. I holländarnas och engelsmännens fall var drivkrafterna till en början mer entydigt ekonomiska, eftersom de var organiserade i ostindiska kompanier. I textböcker om Asien brukar den europeiska handeln ges en stor roll från 1500-talet. Portugiser, holländare och senare engelsmän slog sönder de gamla handelsnätverk som hade funnits mellan olika delar av det maritima Asien och dominerade handeln i ett antal viktiga varor med bryska medel. Det leder till att vi från cirka 1580 har ett globalt omspännande system av handelsvägar, för första gången i världshistorien.

Men återigen, när man går ner och tittar på källmaterialet i detalj så ser man att den västerländska dominansen delvis är en historiografisk fälla. Vi vet t ex att kinesiska sjöburna handlare hade en viktig roll i hamnarna i Sydöstasien, inte minst i de som styrdes av européer. Trots att de kinesiska myndigheterna var skeptiska till att deras undersåtar åkte över haven, var de ett oundgängligt inslag i det ekonomiska livet. Gång på gång uttalade sig koloniala administratörer att de helt enkelt inte skulle klara sig utan sina kineser. De drev butiker, utförde hantverksarbete, tog på sig lägre administrativa uppgifter och begav sig ut på ibland äventyrliga handelsresor som européerna hade föga smak för. Eftersom de var en liten och utsatt minoritet i Sydöstasien var de beroende av mäktiga beskyddare såsom de europeiska kolonialmakterna och kunde av den anledningen sällan bli 'farliga' för västerlänningarna. Tyvärr lämnade dessa 'overseas Chinese' inte efter sig särskilt många skrivna dokument om sin verksamhet, med konsekvenser för hur de har framställts i den historiska litteraturen (Blussé 1996: 148).

Vad var det då som stod på spel när portugiser och holländare levererade batalj den ödesdigra majdagen 1668? Portugiserna bevakade avundsjukt sin tillgång till sandelträ som fanns i stora stånd på öarna Timor och Sumba. Det väldoftande sandelträt användes bland annat för rökelse som hade en stor religiös betydelse i stora delar av Asien. På öarna som portugiserna plundrade fanns vax som användes för ljus och som tätningsämne. Det fanns stora bestånd av sköldpaddor som man hänsynslöst jagade för det värdefulla skalet. Det fanns sjögurka och ätliga fågelbon som kineserna ansåg vara en delikatess och hämtade höga priser. Lite längre bort fanns också pärlor att hämta. Och överallt handlade man med slavar. Både européer och asiater behövde ofri arbetskraft. Det intressanta är att många av dessa varor gick européernas näsor förbi. Nyare forskning har visat att det fanns nätverk som gick över väldiga sträckor i det maritima Sydöstasien där värdefulla naturprodukter och slavar forslades 
från Nya Guinea och Moluckerna i öster mot öarna längre västerut. Asiatiska folkgrupper som cerameser, malajer, bugineser och makassareser seglade sina skepp över havsytor som vare sig portugiser eller holländare kunde övervaka i detalj, trots att de försökte (Ellen 2003). Sådana interna asiatiska strukturer försvagades först då kolonialmakterna fick nya medel att implementera sitt styre. Ångbåtar, moderna vapan, bättre organisation och effektivare informationshantering var några saker som gjorde att Europa alltmer körde över asiatiska samhällen under 1800-talet och början av 1900-talet.

Det sagda erbjuder några exempel på de möjligheter som finns att spåra historiska processer i östra Indonesien och Östtimor under den tidiga koloniala perioden genom en ny läsning av det rikhaltiga koloniala arkivet. Forskning om regionen har en potentiell inspirationskälla i postkolonial teoribildning: utmaningen är att söka se igenom de europeiska texterna och använda dem för att spåra en inhemsk agens och analysera hur de tidiga koloniala miljöerna både visade prov på utbyten och motstånd.

\section{Referenser}

Blussé, Leonard (1996), "The vicissitudes of maritime trade: Letters from the ocean hong merchant, Li Kunhe, to the Dutch authorities of Batavia (1803-09)”, in Anthony Reid (ed.), Sojourners and settlers: Histories of Southeast Asia and the Chinese. Honolulu: University of Hawai'i Press.

Boxer, Charles R. (1947), The Topasses of Timor. Amsterdam: Koninklijke Vereeniging Indisch Instituut.

Ellen, Roy (2003), On the edge of the Banda Zone: Past and present in the social organization of a Moluccan trading network. Honolulu: University of Hawaii Press.

Rodenwaldt, Ernst (1927), Die Mestizen auf Kisar. Batavia: Kolff \& Co.

Roque, Ricardo (2010), Headhunting and colonialism: Anthropology and the circulation of human skulls in the Portuguese Empire, 1870-1930. Houndmills: Palgrave Macmillan. 